\title{
Evaluation of energy consumption in the acceleration process of a passenger car
}

ARTICLE INFO

Received: 30 August 2021

Revised: 12 September 2021

Accepted: 23 September 2021

Available online: 5 December 2021
The analysis of the vehicle acceleration process is a current topic based on the aspects related to the general characteristics of the car, its parameters, design, drive unit performance, and the influence of external factors. However, the ability to accelerate is essential from the point of view of the active safety of the car. Often the dynamic parameters are determined on the basis of the car acceleration test carried out on a level road with good surface in terms of the acceleration time is not reliable and the credibility of such results depends on many factors. Therefore in the article, the authors assessed the dynamic and energy parameters of the car motion, in which the intensity of acceleration of the car with different intensities was examined. The acceleration intensity test was carried out from the set initial speed of the car of $45 \mathrm{~km} / \mathrm{h}$ to the final speed of $120 \mathrm{~km} / \mathrm{h}$ at a constant gear ratio, and the set intensity of the acceleration process resulted from the constant throttle with a constant deflection of the accelerator pedal. Acceleration was carried out in two variants, the first for a normal internal combustion engine and the second for the same engine but additionally equipped with a short-term boost system. In this way, it influences the increase in power and energy in the car drive system, changing its acceleration intensity. Variable car acceleration intensity was obtained in the range from 0.12 to $1.37 \mathrm{~m} / \mathrm{s}^{2}$, and energy consumption at the level of 0.4 to $1.2 \mathrm{MJ}$ in the distance of $1 / 4$ mile. The article proposes a combination of energy parameters and engine power in order to assess the acceleration dynamics, for this purpose, the specific energy consumption of the car was determined, ranging from 0.35 to $2.0 \mathrm{~J} /(\mathrm{kg} \cdot \mathrm{m})$, which was related to the engine power, denoting it with the dynamics index. The study focuses on the assessment of the relationship between the specific energy consumption and acceleration of passenger cars in the available powertrain system using a new dynamics index. The proposed dynamics index combines the energy and dynamic parameters of the car to be able to objectively quantify the acceleration process.

Key words: acceleration, energy consumption, vehicle dynamic, dynamic index

This is an open access article under the CC BY license (http://creativecommons.org/licenses/BY/4.0/)

\section{Vehicle acceleration profile and average driving force}

The acceleration process, regardless of whether it is from a resting state or from a specific initial speed to the set travel speed, is the most energy-consuming phase of motion. Because, even with moderate acceleration, the increase in consumption energy related to fuel consumption significantly exceeds the energy required to overcome the basic motion resistance, and is related to the existence of a fictitious driving force associated with the car inertia depending of total mass. In the thesis [1] the authors analyzes the effects of driving style and vehicle performance on the real-world fuel consumption of conventional vehicles. The authors analyzed that the driving aggressiveness has a important factor of fuel consumption of a vehicle. The work [2] presents a methodology for classifying road traffic energy efficiency. The indicators defined discriminate the impact of the road vertical and horizontal alignments upon energy consumption, disclosing the improvement potential of the road as a function of the traffic origin-destination matrix. On the other hand, the work [3] analyzes the emission of harmful substances into the natural environment depending on the given vehicle speed profile. It has been shown that for the dynamic profiles of the amount of emission they slightly exceed the values given in the approval cycles, and for the profiles with reduced dynamics, the emission values are lower than those obtained in the ap- proval cycle. On the other hand, in [4], a modified fourstroke internal combustion engine was tested, in which the compression ratio was increased. This modification contributed to an improvement in engine power and overall efficiency among others was observed in the tested areas of the characteristics. In the work [5] the authors have undertaken an study into the potential to vary the power output of a powertrain system by application of the digital simulation designed with the purpose of improving the power output of powertrain system in a passenger car comprising a multiratio mechanical gearbox. Therefore, depending on the driver's actions and external conditions, the acceleration process is characterized by different values of both total distance-related and specific energy consumption.

In the case of the acceleration process on a horizontal road with a certain intensity, the energy needed to accelerate the car is balanced by the sum of the energy expenditure lost to overcome the rolling and air resistance, as well as the inertia of the car $[6,7]$. The study [8] analyses the effect of acceleration intensity on energy consumption and drive efficiency during a road test for a passenger vehicle. The authors assessed also the relationship between the average acceleration for the speed gaining phase and unit energy consumption, where the acceleration increment by $0.1 \mathrm{~m} / \mathrm{s}^{2}$ causes a proportional increment in unit total energy consumption by about $0.15 \mathrm{~J} \cdot(\mathrm{kg} \cdot \mathrm{m})^{-1}$, regardless of the acceleration intensity. On the other hand, Kropiwnicki et al. In 
their work [9] analyzed the regenerative braking process for urban traffic conditions. A model was also presented that allows to calculate the amount of energy available from the braking process depending on the proposed variables characterizing the conditions of vehicle traffic. The energy intensity of motion on a horizontal road after the transformation can be expressed by Eq. (1):

$$
\mathrm{E}_{\mathrm{M}}=\mathrm{E}_{\mathrm{R}}+\mathrm{E}_{\mathrm{A}}+\mathrm{E}_{\mathrm{I}}
$$

with the components of the energy balance being recorded by Equations (2)-(5):

- motion energy consumption for the speed gaining phase

$$
E_{M}=\int_{t_{s}}^{t_{e}} D_{F} v d t
$$

- the energy expenditure to overcome rolling resistance

$$
\mathrm{E}_{\mathrm{R}}=\operatorname{mgc}_{\mathrm{R}} \int_{\mathrm{t}_{\mathrm{s}}}^{\mathrm{t}_{\mathrm{e}}} \mathrm{v} \mathrm{dt}
$$

- the energy expenditure to overcome air resistance

$$
E_{A}=\rho / 2 c_{x} A \int_{t_{s}}^{t_{e}} v^{3} d t
$$

- the energy expenditure to overcome inertia resistance is directly proportional to the increase in kinetic energy of the car

$$
\mathrm{E}_{\mathrm{I}}=\frac{\mathrm{m} \delta\left(\mathrm{V}_{\mathrm{e}}^{2}-\mathrm{V}_{\mathrm{S}}^{2}\right)}{2}
$$

In a number of studies, the energy expedited throughout the entire process of the car drive, not only in the acceleration phase, is applied to describe the energy consumption of movement $\left(\mathrm{E}_{\mathrm{M}}\right)$. The authors of the article [10] defines on the possibility of reduction $\mathrm{CO}_{2}$ of the internal combustion engine and presents the analysis based on originally conducted studies. The increase in overall engine efficiency is sought after by all engineers dealing with engine construction, one of the major ways to reduce $\mathrm{CO}_{2}$ emissions is to increase the compression ratio. In turn $\mathrm{Bo} \mathrm{Hu}$ et al. in their work [11] claim that the engine downsizing is a proven approach for achieving a superior fuel efficiency. It is conventionally achieved by reducing the swept volume of the engine and by employing some means of increasing the specific output to achieve the desired installed engine power, usually in the form of an exhaust-driven turbocharger. The article [12] presents the trend of car manufacturers related to the downsizing process of engines and the use of supercharging systems mainly for economic reasons. In turn, the authors of [13] indicate the possibilities of fuel savings through the use of an appropriate style of driving, such as the so-called "pulse and glide" (PnG). In their work, they analyse the savings resulting from the driving style for a traditional vehicle with an ICE engine and for a HEV vehicle. Savings resulting from the driving style can reach even several dozen percent. Mamala et al. in their work [4] claims that one of the ways to improve the efficiency of an IC engine is to raise its compression ratio (CR). However, high $\mathrm{CR}$ in spark ignition engines can be the reason of engine knock in high load and crankshaft rotation speed conditions. Therefore it would be favorable, that high CR would be obtained in low load, and low CR in high load conditions. These results and findings led the authors to build the variable Effective Compression Ratio (eVCR) system. A 4-stroke single cylinder engine was equipped with an electric actuator and its control system, allowing valvetrain-independent intake valve action. The authors of the study [5] have undertaken an study into the potential to vary the power output of a powertrain system by application of the digital simulation-control designed with the purpose of improving the power output of powertrain system in a passenger car comprising a multi-ratio mechanical gearbox.

Taking into account this assumption, it can be utilized to substitute the equation in (2) to the account for total energy consumption relative to movement $\left(\mathrm{E}_{\mathrm{T}}\right)$ resulting from fuel use:

$$
\mathrm{E}_{\mathrm{T}}=\mathrm{SFC} \cdot \mathrm{S}_{\mathrm{F}}
$$

For the case when we consider only the acceleration phase marked by constant conditions, the total energy intensity of motion is given by the product of the mean force and the distance traveled throughout the process of acceleration (7).

The difference in energy consumption resulting from the fuel consumption and the energy delivered to the wheels results from the efficiency of the entire powertrain system, which is given with the expression (8).

$$
E_{T}=\frac{E_{M}}{\eta_{P}}=\frac{D_{F} \cdot L}{\eta_{P}}
$$

It should be noted that the value of a car's mean acceleration during the acceleration phase up to a certain target speed depends exclusively on the implemented speed profile that determines the distance travelled, causing a slight variation in the kinetic energy gain within one gear. The mean acceleration in the acceleration phase depends on the reserve of the driving force and this depends on the gear ratio, i.e., the transmission ratio in powertrain, which will be analyzed in the next chapter.

After the above assumption is applied in the equations (1) and (7), we can express the total distance-related energy consumption in the form

$$
\Psi_{\mathrm{T}}=\frac{\mathrm{E}_{\mathrm{T}}}{\mathrm{L}}
$$

which includes the total of the energy expenditure as well as the efficiency of the powertrain per one meter of the distance traveled by a car.

Given a constant speed, the total distance-related energy consumption is physically equal to the driving force, which also accounts for the term to express the inertia force proportional to the mass and acceleration of the car. Therefore, when we apply the assumption made in eq. (9), the indicator of the movement energy quality of the car, we can develop a parameter that expresses the total specific energy consumption, expressed as the ratio of energy expenditure to the product of mass and distance

$$
\mathrm{Q}_{\mathrm{E}}=\frac{\mathrm{E}_{\mathrm{T}}}{\mathrm{m} \cdot \mathrm{L}}
$$

On a horizontal road, the total specific energy consumption, similarly to eq. (9), is made up by the total of three basic energy terms, of which the first two (eq. (2)) account for the energy losses of basic movement resistance, and the 
third represents the ratio of kinetic energy to the product of mass and distance traveled. Thus, in physical terms, the average acceleration resulting from the energy parameters of the car.

\section{Research methodology and test object}

The article addresses two issues:

The first one: presents the issues of energy consumption assessment in the acceleration process - by introducing the dynamics index.

The second point: presents a system for changing the dynamics of a vehicle in the acceleration process for an internal combustion engine.

For the driver, good dynamic properties of the car are important in the acceleration process. An unsolved problem is the lack of driving force in the acceleration process, which concerns not only the internal combustion engine but also the entire drive system or the way it is controlled by the driver. This problem is also not solved in the case of electric drive systems.

Hence, it is an attempt to use a short-term boost system in an internal combustion engine to improve the car's dynamic properties. It is a response to turbocharging systems with an engine and a generator between the turbine and the compressor. The method of short-term recharging proposed in the work is a simple system in application on an internal combustion engine and requires a minimum of changes. An internal combustion engine with a factory turbocharging system was selected for the tests, for which an additional compressed air supply system was modified and introduced. During the research, the main emphasis was on the dynamics of the car in terms of energy, based on a specific dynamics index. The dynamics index was checked by using a short-term boost system which temporarily increased the power of the internal combustion engine. The basic assumption of the research is to use the same car (same weight) but with a different available power in the drive system. The increase in the power of the combustion engine and the increase in the dynamics of the car is compensated by the proportionally increase in its dynamics index. This made it possible to check the sensitivity of the dynamics index, combining energy and traction parameters.

The use of air charging is one of the methods that allows for obtaining a greater torque from the powertrain during the car's rapid acceleration. The referenced papers [14-17] feature many such air charging systems, starting with air supercharger systems (e.g., mechanically driven compressor and turbocharger) or high-storage systems (e.g., nitrogen monoxide charging). The work [18] is devoted to the analysis of E-tronic systems (control) of superchargers in order to eliminate the Turbo Leg phenomenon. The paper [19] discusses investigations into improving the full-load and transient performance of the Ultraboost extreme downsizing engine by the application of the SuperGen variable-speed centrifugal supercharger. The improvement in full-load performance in the area where the turbocharger cannot generate the required boost by itself is reported. The transient response of the combined system at low engine speed is also presented, together with part-load fuel economy data at several engine speed and load points. On the other hand, in [20] an innovative solution was proposed for the routing of engine exhaust gases, which resulted in a reduction of the exhaust stroke resistance. The proposed method leads to a 5\% fuel economy and provides an improvement in engine performance without significant engine modifications.

Despite their common use in combustion engine supply, the aforementioned systems are characterised by a series of limitations and flaws. One of the major flaws of turbochargers is the adaptation of the compression performance to the engine's rotational speed (excess air at high engine rotational speeds) and the so-called turbocharger lag effect. Therefore, research on new air supercharger structures can be divided into three categories with the following characteristics:

- variable supercharger specification,

- combined systems,

- combining superchargers into assemblies.

The use of a turbocharger, despite substantially improving the torque parameters, is not without flaws either and does not solve the problem of lacking a turbocharger. The lacking turbocharger is the reason for deficiencies in the driving force. When the demand for torque rapidly increases at the crankshaft's low rotational speed, the insufficient turbine fuelling prevents the compressor from supplying sufficient air quantity to meet the condition related to the excess air ratio $\lambda=1$. The delay in the powertrain's reaction to the driving force demand and as well as the phenomenon of a gas connection in the intake manifold of the turbocharger system is the subject of research of many scientists [21,22]. Despite the flaw, this solution is most often used by engine manufacturers, however, new solutions feature a complex structure. The detailed schematic of the short-term compressed air supercharging system upstream of the turbocharger assembly is presented in Fig. 1.

The application of the short-term supercharging directly into the turbocharger's assembly in the quantity required to overcome the resistance of gas flow through the compressor will enable a vacuum less engine supercharging with air required to accelerate it. This solution is based on a classic turbocharger assembly, in which the turbine was modified by placing an expansion nozzle supplying compressed air directly to the turbine's blades. This substantially improves the increase in the turbine's rotational speed in the conditions of its reduced performance. The adoption of these assumptions should have a positive impact on the car's acceleration dynamics.

The bench testing, conducted on the MAHA MSR 500 $4 \times 4$ chassis dynamometer, utilised a passenger car with a spark ignition engine with an indirect multipoint fuel injection and a turbocharger system, with the displacement of $1,781 \mathrm{~cm}^{3}$ and a maximum power of $110 \mathrm{~kW}$ at 5,700 $\mathrm{rpm}$ and a torque of $210 \mathrm{Nm}$ at $1,750 \mathrm{rpm}$, equipped with an electronically-controlled throttle. The power transmission system is equipped with a manual five-speed gearbox. The car's maximum speed amounted to $223 \mathrm{~km} / \mathrm{h}$. The test car with elements of the modified turbocharging system is shown in Figs 2a, $2 b$. 


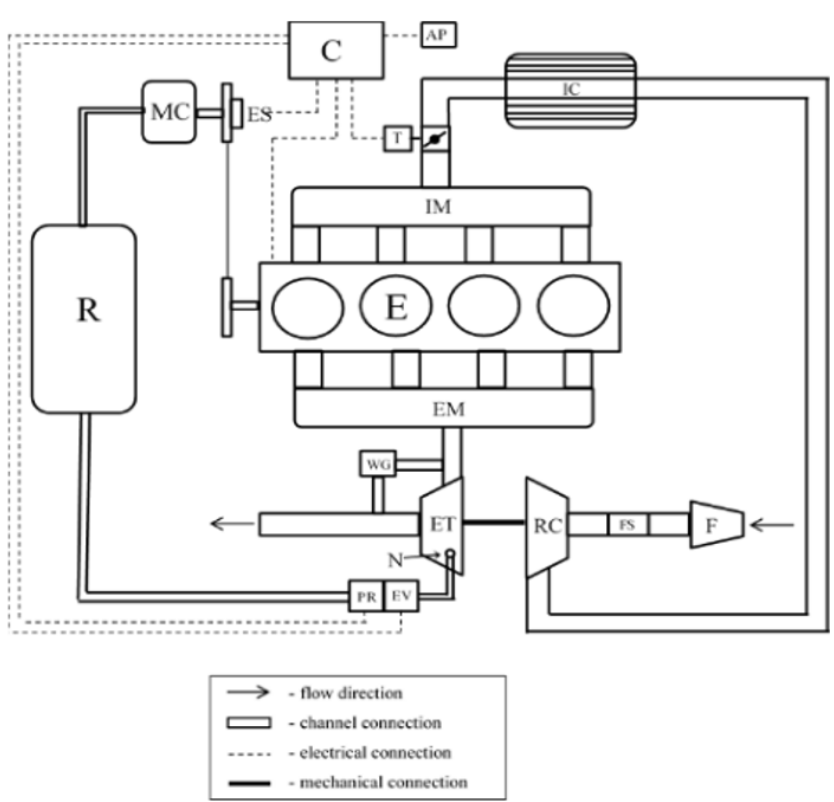

Fig. 1. Short-term compressed air supercharging system downstream of the turbocharger assembly: E - engine, EM - exhaust manifold, WG - west gate, ET - exhaust turbine, PR - pressure regulator, T - throttle, EC electromagnetic clutch, F - air filter, RC - radial compressor, IC - intercooler, IM - intake manifold, C - controller, AP - accelerator/throttle pedal, $\mathrm{R}$ - reservoir, FS - mass airflow sensor, $\mathrm{EV}$ - valve, $\mathrm{MC}$ - mechanical compressor, $\mathrm{N}$ - nozzle

a)

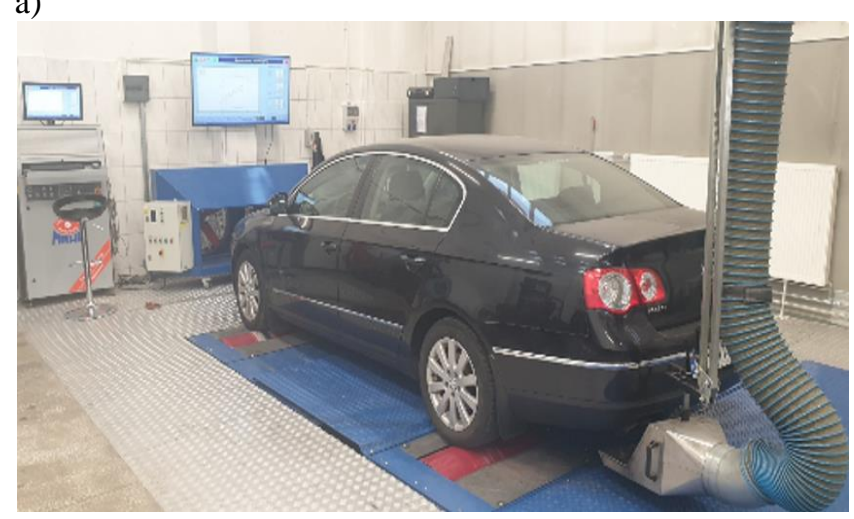

b)

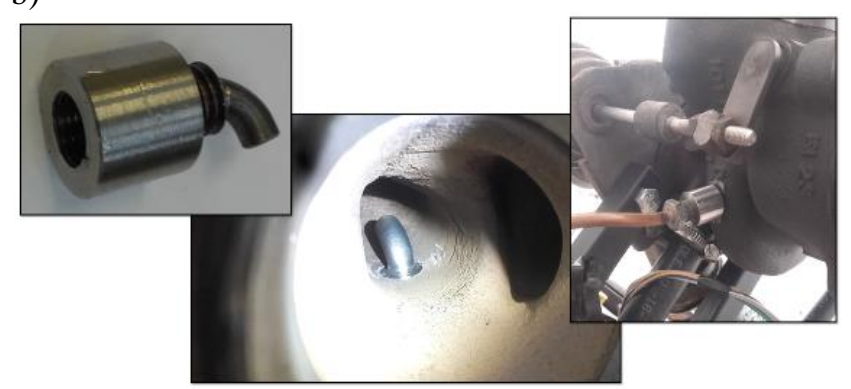

Fig. 2. Test car with a modified supercharging system: a) test vehicle, b) turbocharger assembly's

The test setup comprised an autonomous control and measurement system in the LabView environment, which resulted as an integrated application that enables controlling and recording of powertrain operating parameters during the repeatability of the flexibility test and observ- ing of the acceleration process. To record the kinematic parameters of a passenger car in motion, a measurement system called PAAF II (Power Acceleration and Force) developed in the Department of Vehicles at the Opole University of Technology was used, which was programmed in the LabView environment. For the purposes of measurements, this software has been supplemented with a control module for the control of the additional power increase of the powertrain. It enables the recording of kinematic parameters with time from the following systems:

- from the OBDII on-board diagnostic system recording, among other parameters: engine speed, throttle position, intake manifold pressure, engine load, fuel consumption, vehicle speed,

- from additional direct devices using a measurement module: recording speed, distance by means of the Corrsys Datron L-350 optical head, throttle position, accelerator pedal, position and consumed fuel from the Flowtronic system,

- from the on-board data transmission network-based CAN BUS: standard recording engine speed, wheel acceleration, distance travelled, gear number, driver's control pedal status, and fuel consumption,

- from the supercharging system among other parameters: charging pressure.

The bench testing was conducted to obtain a detailed image about the impact of the short-term compressed air supercharging directly onto the turbine's blades via an expansion nozzle, the end of which is connected to the intake channel of the engine's exhaust manifold. The air was fed from the storage tank at the pressure of $0.9 \mathrm{MPa}$ directly to the turbine blades during car acceleration on a chassis dynamometer. The air supercharging time amounted to $10 \mathrm{~s}$, with an average air flow of about $62 \mathrm{dm}^{3} / \mathrm{s}$. Different tank pressures and flows were tested in the study, but the results presented below refer to these settings. The tests were carried out to identify the total energy consumption, in the process of acceleration with the use of the active identification method, by observing the parameters of the powertrain operation in dynamic conditions. Therefore, the subject of further considerations is the analysis of the process of passenger car acceleration from a fixed initial speed, on a horizontal road, to a fixed final speed. The final value of the car's speed results from the balance of energy in the powertrain with the energy of motion resistance or the assumed final speed of $120 \mathrm{~km} / \mathrm{h}$ achieved by the car. The intensity of the acceleration process was regulated by a constant depression of the accelerator pedal, corresponding to a throttle position in the intake manifold of $20 \%$, $25 \%, 30 \%, 35 \%, 40 \%, 45 \%, 50 \%, 70 \%$, and $100 \%$ of the range during the test on distance $1 / 4$ mile. The acceleration process was carried out on constants transmission ratios in the powertrain.

\section{Test results}

The flexibility test carried out during the acceleration process of the car over a quarter of a mile was analysed for the mean values of kinematic and energy parameters were determined (Fig. 3). 


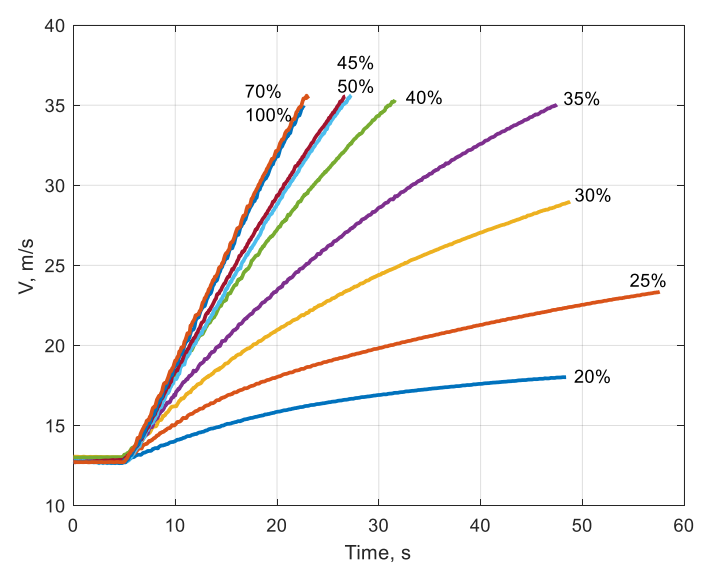

Fig. 3. Courses of linear speed car in the flexibility test during acceleration of a constant transmission on the test bench for constant throttle positions

For the throttle positions equal to $20 \%, 30 \%$, and $35 \%$, resulting from the most frequent driving operating conditions in particular for economic driving, the test was realized up to the maximum speed that can be gained for a given throttle position, because the driving force in the powertrain system, in accordance with the equation (1) was not sufficient to reach the desired speed. The value of the force results from the quotient of the efficiency of the powertrain, i.e., the energy delivered to the powertrain in relation to the length of the road taken for acceleration. Due to the different dynamics of the flexibility test, the value of the speed achieved over the distance of $1 / 4$ mile is variable. The averaged kinematic parameters recorded during the acceleration process in the $1 / 4$ mile elasticity test are summarized in Table 1.

Table 1. List of dynamic and energy parameters for the acceleration process in $1 / 4 \mathrm{mil}$

\begin{tabular}{|c|c|c|c|c|c|c|}
\hline $\begin{array}{c}\mathrm{TP} \\
{[\%]}\end{array}$ & $\mathrm{a}_{\text {sf }}$ & $\begin{array}{c}\text { Time } \\
{[\mathrm{s}]}\end{array}$ & $\begin{array}{c}\mathrm{L} \\
{[\mathrm{m}]}\end{array}$ & $\begin{array}{c}\mathrm{a}_{\max } \\
{\left[\mathrm{m} / \mathrm{s}^{2}\right]}\end{array}$ & $\begin{array}{c}\mathrm{P}_{\text {mean }} \\
{[\mathrm{kW}]}\end{array}$ & $\begin{array}{c}\mathrm{Q}_{\text {mean }} \\
{\left[\mathrm{dm}^{3} / 100 \mathrm{~km}\right]}\end{array}$ \\
\hline 20 & 0.11 & 25.9 & 401.2 & 0.25 & 4.53 & 6.93 \\
\hline 25 & 0.17 & 23.5 & 401.5 & 0.41 & 7.73 & 7.86 \\
\hline 30 & 0.34 & 23.5 & 401.8 & 0.67 & 10.34 & 9.71 \\
\hline 35 & 0.51 & 19.7 & 400.8 & 0.83 & 18.99 & 12.29 \\
\hline 40 & 0.85 & 18.4 & 401.4 & 1.13 & 26.32 & 15.58 \\
\hline 45 & 1.06 & 17.6 & 402.8 & 1.18 & 32.67 & 18.26 \\
\hline 50 & 1.08 & 17.6 & 401.4 & 1.23 & 33.13 & 18.66 \\
\hline 70 & 1.30 & 16.8 & 400.5 & 1.36 & 40.57 & 22.88 \\
\hline 100 & 1.31 & 16.7 & 400.8 & 1.37 & 40.96 & 22.92 \\
\hline
\end{tabular}

\section{Evaluation of the energy consumptions}

\section{in acceleration process of a passenger car}

The results of fuel consumption versus time recorded during the test of car acceleration elasticity with different throttle positions were compared to the mean acceleration values and subsequently to the fuel consumption $\left[\mathrm{dm}^{3} / 100\right.$ km] (Fig. 4). The fuel consumption related to the cases marked by small values of acceleration is constant and independent of acceleration, however, for the maximum intensity of acceleration, this value varies within a wide range. It can be generalized that the low acceleration up to the value of the mean acceleration of $0.8 \mathrm{~m} / \mathrm{s}^{2}$ does not generate significant variations in fuel consumption. Above this value, the consumption increases significantly.

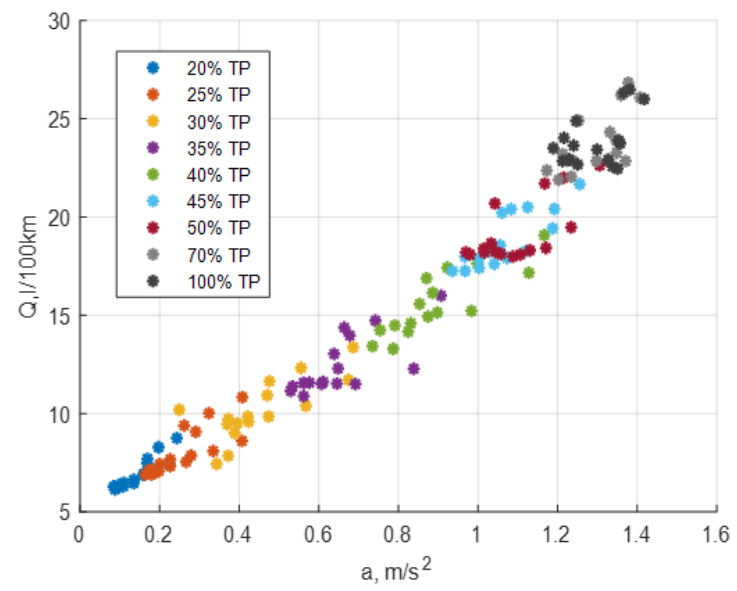

Fig. 4. Variations in distance-related fuel consumption in the acceleration elasticity test of a vehicle with constant transmission on dynamometer for constant throttle positions

In terms of the mean values resulting from the car acceleration elasticity test, the mean values are directly proportional to both fuel consumption and distance-related fuel consumption. It is difficult to relate these values to the dynamics resulting from the varied available energy in the drive system, which is indicated by the total energy consumption of car movement and is presented in Table 2 .

Table 2. List of energy parameters for the acceleration process in $1 / 4$ mile test

\begin{tabular}{|c|c|c|c|c|c|}
\hline $\begin{array}{c}\mathrm{TP} \\
{[\%]}\end{array}$ & $\begin{array}{c}\mathrm{Ge}_{\text {mean }} \\
{[\mathrm{g} / \mathrm{s}]}\end{array}$ & $\begin{array}{c}\mathrm{Q}_{\min } \\
{\left[\mathrm{dm}^{3} / \mathrm{km}\right]}\end{array}$ & $\begin{array}{c}\mathrm{Q}_{\max } \\
{\left[\mathrm{dm}^{3} / 100 \mathrm{~km}\right]}\end{array}$ & $\begin{array}{c}\mathrm{E}_{\mathrm{T}} \\
{[\mathrm{MJ}]}\end{array}$ & $\begin{array}{c}\mathrm{Q}_{\mathrm{E}} \\
{[\mathrm{J} /(\mathrm{kg} \cdot \mathrm{m})]}\end{array}$ \\
\hline 20 & 0.780 & 6.28 & 7.96 & 0.441 & 0.355 \\
\hline 25 & 0.967 & 6.89 & 9.63 & 0.496 & 0.519 \\
\hline 30 & 1.219 & 7.41 & 11.71 & 0.550 & 0.688 \\
\hline 35 & 1.795 & 11.38 & 15.20 & 0.720 & 1.061 \\
\hline 40 & 2.446 & 14.24 & 17.16 & 0.888 & 1.404 \\
\hline 45 & 3.017 & 17.25 & 19.41 & 1.024 & 1.664 \\
\hline 50 & 3.088 & 17.98 & 19.62 & 1.033 & 1.691 \\
\hline 70 & 4.005 & 22.04 & 23.89 & 1.232 & 2.003 \\
\hline 100 & 4.056 & 21.48 & 24.03 & 1.224 & 2.008 \\
\hline
\end{tabular}

The registered differences in terms of the total energy consumption of the investigated car can be related to its mass. Hence, in accordance with the definition derived from equation (6), the cumulative energy consumption over the entire process of acceleration that is related to mass and distance and is expressed in the physical sense by the measure expressed by $\mathrm{m} / \mathrm{s}^{2}$, that is, the value of the mean acceleration accompanying power supply to the wheels.

\section{Evaluation of the acceleration process of a passenger car}

The effect of the additional air charging of the turbocharger unit was measured on a chassis dynamometer in the form of an increase in the driving force during car acceleration from its initial speed, with a constant throttle position (Fig. 5). According to the literature data [23, 24] as well as 
the information presented in the introduction, a higher increase in driving force at partial throttle opening was achieved. The increase varies depending on the throttle opening.

a)

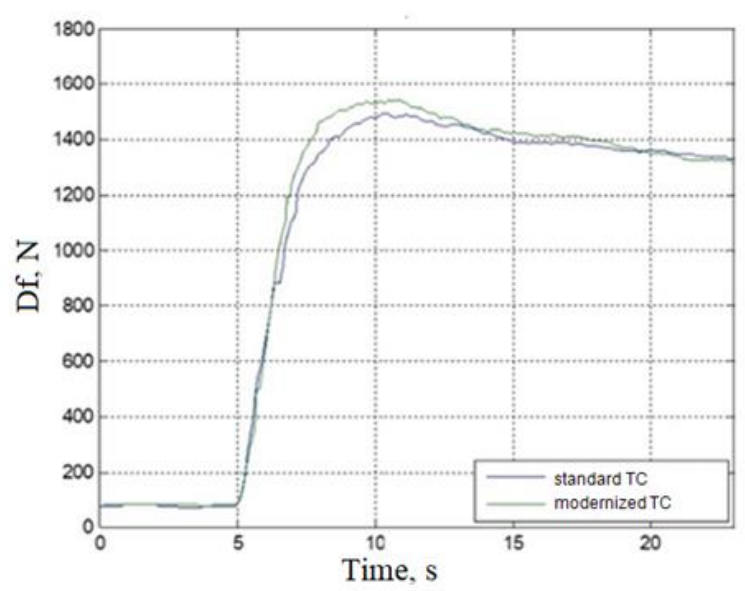

b)

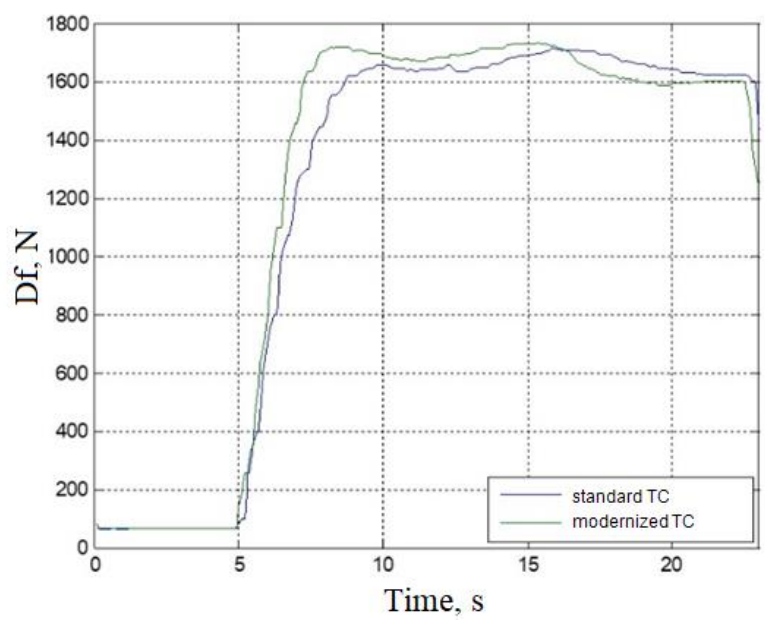

Fig. 5. Comparison of the driving forces (Df) during acceleration with and without the supercharger system for different throttle positions

The obtained higher driving force values improved the acceleration, especially in the first acceleration phase. The engine test bench was used to conduct tests of car acceleration after rapid throttle opening from its initial position of $7 \%$ to the end position during a constant transmission ratio. The initial throttle opening angle corresponded to the car's linear speed of $45 \mathrm{~km} / \mathrm{h}$, while the end throttle opening angle derived from the force balance or the measurement was interrupted after achieving the end speed of $125 \mathrm{~km} / \mathrm{h}$, which is presented in Fig. 5.

In order to analyze the sensitivity of the car dynamics related to the increase in powertrain output power, the tests were repeated for the tested car with the activated system that increases the instantaneous power in the powertrain by increasing the engine power. The comparisons of the powertrain performance during the flexibility test with different throttle openings are presented in Fig. 6.

Table 3 shows the increase in engine power with a constant position of the acceleration pedal in the boost process. The relative increase in engine power during recharging ranges from 5.7 to $12.4 \%$. The best effect was achieved with the accelerator pedal $45 \%$. The smallest increase in power was achieved at full engine load.

a)

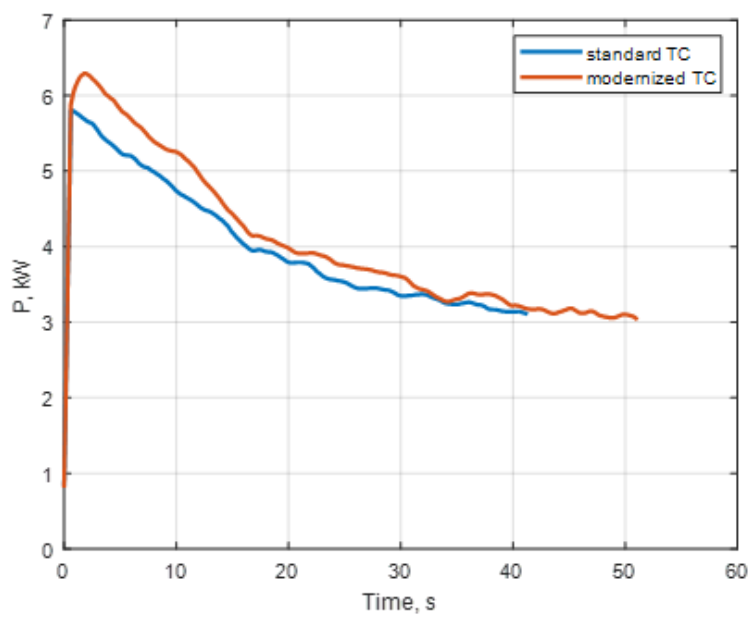

b)

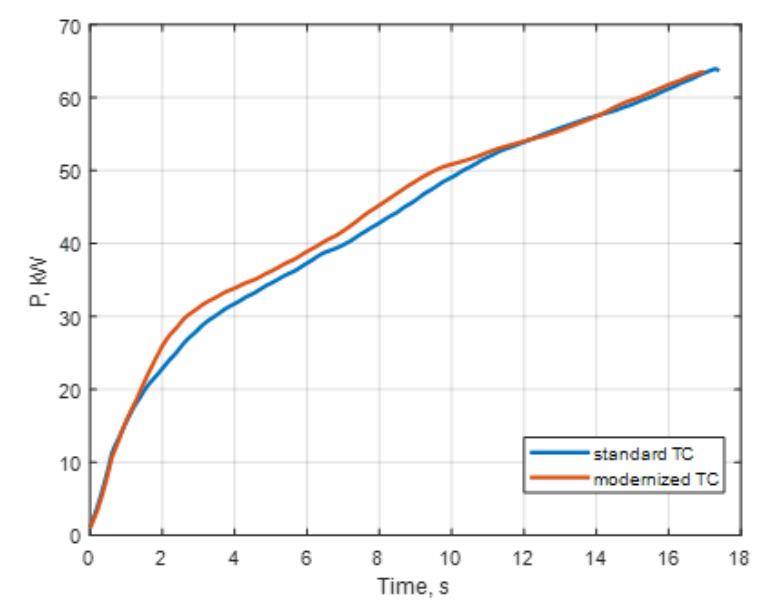

Fig. 6. Comparison of the powertrain output in the car acceleration elasticity test for a car with step-gear transmission on a dynamometer for throttle positions: a) $20 \%$, b) $100 \%$

Table 3. Increase in the engine power for a constant position of the accelerator pedal

\begin{tabular}{|l|c|c|c|c|c|c|c|c|}
\hline \multicolumn{1}{|c|}{ Accelerator position, \% } \\
\hline 20 & 25 & 30 & 35 & 40 & 45 & 50 & 70 & 100 \\
\hline \multicolumn{8}{|c|}{ Relative power gain during supercharging, \% } \\
\hline 7.8 & 6.3 & 6.2 & 8.2 & 8.2 & 12.4 & 8.1 & 9.5 & 5.7 \\
\hline
\end{tabular}

During the supercharging, a temporary increase in fuel consumption was observed (Fig. 7), which is the result of the increased amount of air flowing in the engine cylinder. It is tantamount to the increase in engine power, and Fig. 7 shows the fuel consumption for the reduced positions of the accelerator pedal, i.e., the minimum and mass of the car acceleration.

The modifications to the turbocharger assemblies in the form of short-term supercharger system allowed for achieving the linear speed within a shorter time. After the shortterm charging is completed, the injected fuel dose to the engine drops sharply, which is shown in Fig. 7. This may 
be due to the fuel dose correction based on too high oxygen content in the exhaust gas caused by compressed air charging. It was possible to observe the following dependencies: the smaller the throttle opening angle during acceleration, the greater the importance of the short-term supercharger system are shown in Fig. 8.

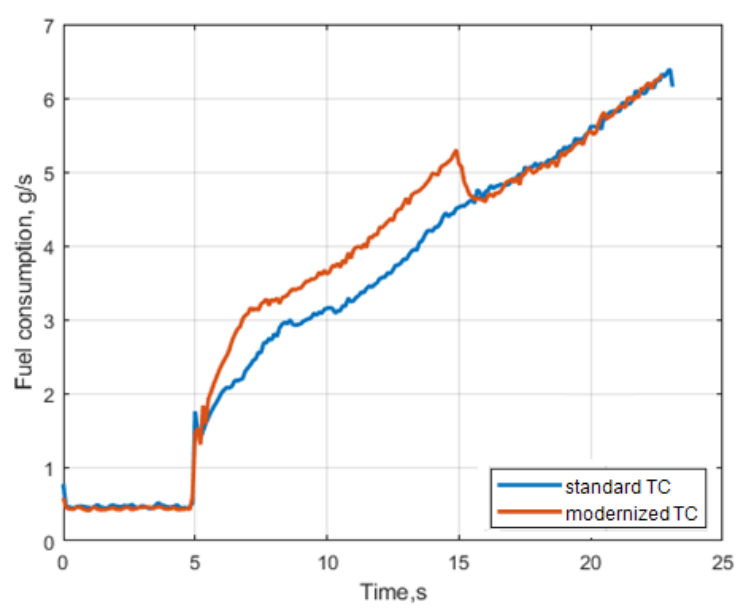

Fig. 7. Fuel consumption in the car acceleration elasticity test on a dynamometer for throttle positions $100 \%$

a)

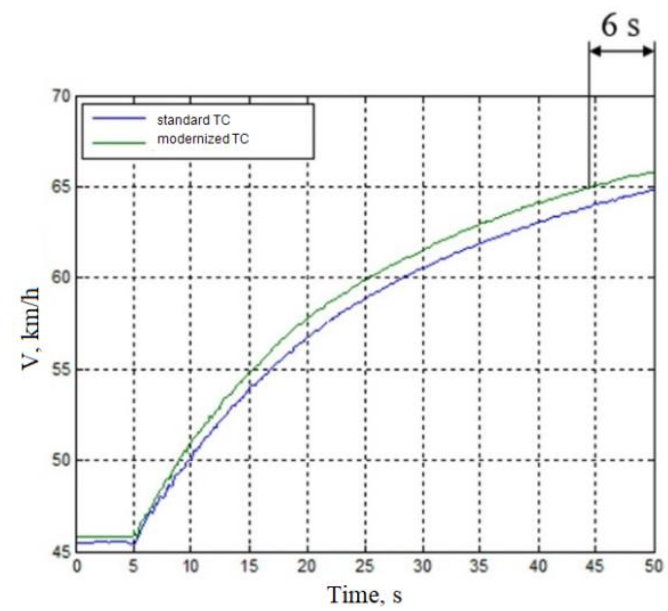

b)

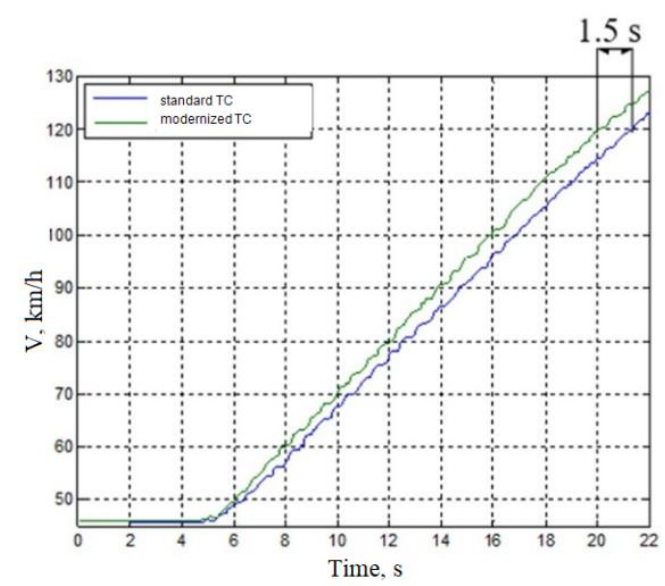

Fig. 8. Comparison of the driving forces during acceleration with and without the supercharger system for different throttle positions: a) $20 \%$, b) $100 \%$
For the final throttle position of $20 \%$ (Fig. 8a), achieving the final linear speed of $65 \mathrm{~km} / \mathrm{h}$ took $45 \mathrm{~s}$ in the case of the traditional engine with a supercharger system and $6 \mathrm{~s}$ less in the case of an engine utilising the supercharging. Similarly, for the throttle position of $100 \%$ (Fig. 8b), the time was shorter by $1.5 \mathrm{~s}$.

The presented graphs of the speed increase of the car in the flexibility test depend on the energy consumption and dynamics of the car and are directly related to the power output of the drive system, so they are difficult to compare $[8,25,26]$. In order to assess the car acceleration processes in the flexibility test, the specific energy consumption of the car was compared to the power of the drive unit. An additional index of the energy quality of the acceleration of the car was obtained according to eq. (10).

$$
\mathrm{I}_{\mathrm{D}}=\frac{\mathrm{P}}{\mathrm{Q}_{\mathrm{E}}}
$$

The introduced dynamics index is a universal measure, which in its properties is related to power, mass, and distance traveled, which in this way combines energy parameters with dynamics. The applied dynamics index demonstrates in the physical sense the time $1 \mathrm{~s}$ needed for the acceleration of a passenger car weighing $1 \mathrm{~kg}$ over a distance of $1 \mathrm{~m}$, combining the basic kinematic properties of its movement. These quantities are known and have long been used in the automotive industry.

The achieved in the supercharging process increased engine power affects the acceleration time, but these changes are insignificant in relation to the introduced acceleration dynamics index (Fig. 9). In the case of the position of the acceleration pedal of $20 \%$ (for a low intensity of car acceleration), these differences are minimal and amount finally to $12.74 \mathrm{~kg} \cdot \mathrm{m} / \mathrm{s}$ with the fuel consumption of $6.94 \mathrm{dm}^{3} / 100 \mathrm{~km}$. For a full deflection of the accelerator pedal of $100 \%$, the maximum intensity of acceleration of the car, the index increases to the value of $20.24 \mathrm{~kg} \cdot \mathrm{m} / \mathrm{s}$ with a much greater increase in fuel consumption depending on the traveled distance $22.93 \mathrm{dm}^{3} / 100 \mathrm{~km}$.

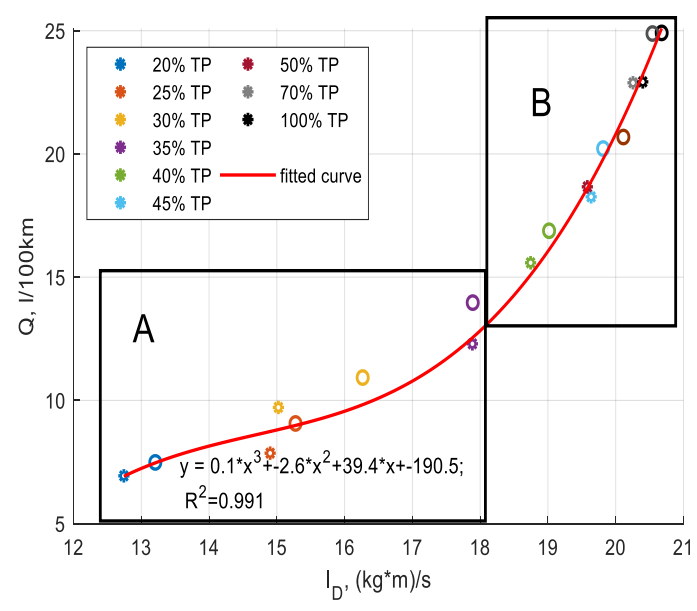

Fig. 9. Index of acceleration dynamics for throttle positions

The car acceleration energy quality indicator corresponds to the kinematic parameters of the car. Using the motion dynamics index $\left(\mathrm{I}_{\mathrm{D}}\right)$ as in Fig. 9, two areas can be 
determined. Area A is the area of moderate car acceleration intensity up to $0.8 \mathrm{~m} / \mathrm{s}^{2}$ for the acceleration pedal value up to $45 \%$. This is an area where the energy consumption of traffic is of great importance, related to the parameters of the car and the acceleration profile. Area B is the area assigned to engine power where the increase in acceleration intensity is due to the increase in engine power. With higher car acceleration intensity, the dynamics index $\left(\mathrm{I}_{\mathrm{D}}\right)$ increases, which is consistent with physics due to the higher energy expenditure (Fig. 9) and the fuel consumption increases significantly. For the presented dynamics index, the instantaneous increase in engine power and acceleration intensity is compensated by the specific energy consumption of the car and the index is comparable.

\section{Conclusion}

In conclusion, it should be emphasized that the analysis of car acceleration processes is a complex process. A direct comparison based on the acceleration time is unreliable. As the research result has shown, of a temporary increase in the power of the combustion engine by approx. $5 \mathrm{~s}$, different acceleration times were achieved for the same drive system with constant control parameters (for example as constant throttle positions). The time reduction is a consequence of the increase in fuel consumption and thus the specific energy consumption of the car. However, the reference to the power in the drive system results in a comparable dynamics index of the car's acceleration. The dynamics index in its properties is related to the parameters of movement (time, speed), the design parameters of the car (mass, coefficient of aerodynamic drag) as well as the parameters of the drive system (engine power).
At the same time, the presented in the paper solution supports the car acceleration process using short-term engine supercharging with compressed air is an effective method of improving the car acceleration intensity. The use of shortterm turbocharger boost using compressed air gives much greater benefits in the event of partial throttle opening, resulting in a $13.3 \%$ reduction in acceleration time, which is especially important in city traffic. As the results show, a shortterm increase in fuel consumption does not affect the total specific energy consumption of the car. Similar work leading group Jaguar Land Rover Ltd in 2016 in Great Britain, GB, who reported Patent No. GB1612798.7A, charging system for air turbine blades to increase efficiency and solve the problem of "turbo lag" [27].

The article presents an assessment of the acceleration process of a passenger car equipped with an internal combustion engine, in which it is possible to increase the instantaneous power. The presented dynamics index characterizes the car acceleration process and combines the dynamic and energetic parameters of this process. Such a combination allows for meaningful comparisons of the acceleration process. In further research, using the dynamics index, it is intended to compare the acceleration process with a hybrid drive system, where the total increase in power in the drive system is much greater. In addition, the process of the temporary increase in power by the internal combustion engine must be compatible with the control of the gear ratio in the drive system [24]. Then we can achieve better work results with lower energy consumption, the acceleration process, but this also requires further work.

\section{Nomenclature}

$\Psi_{\mathrm{T}} \quad$ distance-related energy consumption $[\mathrm{kJ} / \mathrm{m}]$

$\mathrm{Q}_{\mathrm{E}} \quad$ total specific energy consumption $\left[\mathrm{kJ} / \mathrm{m} \cdot \mathrm{kg}^{-1}\right]$

a acceleration $\left[\mathrm{m} / \mathrm{s}^{2}\right]$

A frontal surface of the vehicle $\left[\mathrm{m}^{2}\right]$

AP accelerator/throttle pedal

$\mathrm{a}_{\mathrm{sf}} \quad$ slope factor

C controller

$\mathrm{C}_{\mathrm{R}} \quad$ rolling resistance coefficient

$\mathrm{C}_{\mathrm{x}} \quad$ drag coefficient

$\mathrm{D}_{\mathrm{F}} \quad$ mean acceleration force $[\mathrm{N}]$

DMC deviation from the mean confidence data

$\mathrm{E}$ engine

$\mathrm{E}_{\mathrm{A}}$ energy of air resistance $[\mathrm{kJ}]$

EC electromagnetic clutch,

$\mathrm{E}_{\mathrm{H}}$ energy of gradient resistance [kJ]

$\mathrm{E}_{\mathrm{I}}$ energy of inertia $[\mathrm{kJ}]$

EM exhaust manifold

$E_{M} \quad$ energy of motion $[\mathrm{kJ}]$

$E_{R} \quad$ energy of rolling resistance $[\mathrm{kJ}]$

ET exhaust turbine

$\mathrm{E}_{\mathrm{T}}$ total energy consumption [MJ]

EV valve

$\mathrm{F}$ air filter

FC Fuel consumption in test [g]

$F_{D} \quad$ driving force in the phase when power is supplied to the wheels [N]
$\mathrm{F}_{\mathrm{PT}} \quad$ driving force $[\mathrm{N}]$

FS mass airflow sensor

g gravitational acceleration $\left[\mathrm{m} / \mathrm{s}^{2}\right]$

$\mathrm{Ge}$ fuel consumption $[\mathrm{g} / \mathrm{s}]$

IC intercooler

$\mathrm{I}_{\mathrm{D}} \quad$ Dynamic Index $[\mathrm{kg} \cdot \mathrm{m} / \mathrm{s}]$

IM intake manifold

$\mathrm{L}$ distance $[\mathrm{m}]$

$\mathrm{m}$ mass [kg]

MC mechanical compressor

$\mathrm{N}$ nozzle

$\mathrm{P} \quad$ power $[\mathrm{kW}]$

$\mathrm{P}_{\text {mean }}$ mean power $[\mathrm{kW}]$

PR pressure regulator

Q distance-related fuel consumption $\left[\mathrm{dm}^{3} / 100 \mathrm{~km}\right]$

$\mathrm{R}$ reservoir

$\mathrm{RC}$ radial compressor

$\mathrm{S}_{\mathrm{F}} \quad$ calorific value $[\mathrm{MJ} / \mathrm{kg}]$

SFC specific fuel consumption $[\mathrm{g} / \mathrm{kWh}]$

SI Spark Ignition engine

T throttle

TC turbocharger

$\mathrm{t}_{\mathrm{e}} \quad$ end time [s]

TP throttle position [\%]

$\mathrm{t}_{\mathrm{s}} \quad$ start time [s]

$\mathrm{v}$ instantaneous speed of the vehicle $[\mathrm{m} / \mathrm{s}]$ 


\begin{tabular}{llll}
\hline $\mathrm{V}$ & speed profile $[\mathrm{m} / \mathrm{s}],[\mathrm{km} / \mathrm{h}]$ & $\rho$ & air density $\left[\mathrm{kg} / \mathrm{m}^{3}\right]$ \\
$\mathrm{V}_{\mathrm{e}}$ & end speed $[\mathrm{m} / \mathrm{s}]$ & $\delta$ & rotating mass coefficient \\
$\mathrm{V}_{\max }$ & highest vehicle speed $[\mathrm{m} / \mathrm{s}]$ & & \\
$\mathrm{V}_{\mathrm{s}}$ & start speed $[\mathrm{m} / \mathrm{s}]$ & & maximum value of a parameter \\
$\mathrm{WG}$ & west gate & $\max$ & $\begin{array}{l}\text { minimum value of a parameter } \\
\eta\end{array}$ \\
$\eta_{\mathrm{P}}$ & tofficiency & mean & mean value of a parameter
\end{tabular}

\section{Bibliography}

[1] BERRY, M. The effect of driving style and vehicle performance on the real-world fuel consumption of US Light-Duty Vehicles. Massachusetts Institute of Technology. 2010. https://web.mit.edu/sloan-auto-

lab/research/beforeh2/files/IreneBerry_Thesis_February2010.pdf

[2] FERREIRA, H., RODRIGUES, C.M., PINHO, C. Impact of road geometry on vehicle energy consumption and $\mathrm{CO}_{2}$ emissions: An energy-efficiency rating methodology. Energies. 2020, 13(1), 119. https://doi.org/10.3390/en13010119

[3] FONTARAS, G., FRANCO, V., DILARA, P. et al. Development and review of Euro 5 passenger car emission factors based on experimental results over various driving cycles. Science of The Total Environment. 2014, 468-469, 10341042. https://doi.org/10.1016/j.scitotenv.2013.09.043

[4] MAMALA, J. GRABA, M. PRAZNOWSKI, K. et al. Control of the effective pressure in the cylinder of a SparkIgnition engine by electromagnetic valve actuator. SAE Technical Paper 2019-01-1201. 2019.

https://doi.org/10.4271/2019-01-1201

[5] PRAŻNOWSKI, K., MAMALA, J., BIENIEK, A. Potential application of power output control in the powertrain of a passenger car. IOP Conference Series: Materials Science and Engineering. 2018, 421(2), 1-10.

https://doi.org/10.1088/1757-899X/421/2/022027

[6] RILL, G. Road Vehicle Dynamics: Fundamentals and Modeling - 1st Edition. CRC Press. 2011.

https://www.routledge.com/Road-Vehicle-Dynamics-

Fundamentals-and-Modeling/Rill/p/book/9781439838983 (accessed on 11.06.2021).

[7] GILLESPIE, T.D. Fundamentals of vehicle dynamics. SAE International. Warrendale 1992.

[8] GRABA, M., MAMALA, J., BIENIEK, A. et al. Impact of the acceleration intensity of a passenger car in a road test on energy consumption. Energy. 2021, 226, 120429.

https://doi.org/10.1016/j.energy.2021.120429

[9] KROPIWNICKI, J., FURMANEK, M. Analysis of the regenerative braking process for the urban traffic conditions, Combustion Engines. 2019, 178(3), 203-207. https://doi.org/10.19206/ce-2019-335

[10] DRABIK, D., MAMALA, J., ŚMIEJA, M. et al. Possibility of reducing $\mathrm{CO}_{2}$ emissions from internal combustion engines. E3S Web of Conferences. International Conference Energy, Environment and Material Systems. 2017, 19, 1-4. https://doi.org/10.1051/e3sconf/20171901013

[11] HU, B., TURNER, J., AKEHURST, S. et al. Observations on and potential trends for mechanically supercharging a downsized passenger car engine: a review. Proceedings of the Institution of Mechanical Engineers, Part D: Journal of Automobile Engineering. 2016, 231(4), 435-456. https://doi.org/10.1177/0954407016636971

[12] KUSZTELAN, A., YAO, Y.F., MARCHANT, D.R. A review of novel turbocharger concepts for enhancements in energy efficiency. The International Journal of Thermal \& Environmental Engineering. 2011, 2(2), 75-82. https://doi.org/10.5383/ijtee.02.02.003
[13] LEE, J., NELSON, D.J., LOHSE-BUSCH, H. Vehicle inertia impact on fuel consumption of conventional and hybrid electric vehicles using acceleration and coast driving strategy. SAE Technical Paper 2009-01-1322. 2009. https://doi.org/10.4271/2009-01-1322

[14] MELDOLESI, R., BADAIN, N. Scuderi split cycle engine: air hybrid vehicle powertrain simulation study. SAE Technical Paper 2012-01-1013. 2012. https://doi.org/10.4271/2012-01-1013

[15] MERKISZ, J., PIELECHA, J., RADZIMIRSKI, S. New Trends in Emission Control in the European Union. Springer International Publishing. Cham 2014.

https://doi.org/10.1007/978-3-319-02705-0

[16] MYSŁOWSKI, J. Doładowanie silników [Supercharging of internal combustion engines]. Wydawnictwa Komunikacji $i$ Łączności. Warszawa 2016.

[17] Nithesh, N. P. S, Effect of splitters in recirculation channels on performance of turbocharger compressors used in gasoline engines - a CFD study. International Journal of Automotive and Mechanical Engineering. 2019, 16(1), 62146229. https://doi.org/10.15282/ijame.16.1.2019.10.0472

[18] SIVARAMAN, M., AAKASH, A., BHARATHIRAJA, B. et al. Design and performance analysis on E-Tronic turbocharger to eliminate turbo lag. International Journal of Pure and Applied Mathematics. 2018, 119(12), 15687-15700. https://acadpubl.eu/hub/2018-119-12/articles/6/1452.pdf

[19] Turner, J.W.G. Popplewell, A. Marshall, D.J. et al. SuperGen on Ultraboost: Variable-Speed Centrifugal Supercharging as an Enabling Technology for Extreme Engine Downsizing. SAE International Journal of Engines. 2015, 8(4), 1602-1615. https://doi.org/10.4271/2015-01-1282

[20] WILliaMS, A., BAKER, A., GARNER, C. Turbodischarging: predicted improvements in engine fuel economy and performance. SAE Technical Paper 2011-01-0371. 2011. https://doi.org/10.4271/2011-01-0371

[21] BOZZA, F., DE BELLIS, V., MARELLI, S. et al. 1D simulation and experimental analysis of a turbocharger compressor for automotive engines under unsteady flow conditions. SAE International Journal of Engines. 2011, 4(1), 13651384. https://doi.org/10.4271/2011-01-1147

[22] KOŁODZIEJ, S., LIGUS, G., MAMALA, J. et al. Analysis of air flow velocity distribution in the intake system of an SI engine, Combustion Engines. 2017, 169(2), 152-157. https://doi.org/10.19206/CE-2017-227

[23] BIENIEK, A., GRABA, M., HENNEK, K. et al. Analysis of fuel consumption of a spark ignition engine in the conditions of a variable load. MATEC Web of Conferences. 2017, 117, 1-6. https://doi.org/10.1051/matecconf/201711800036

[24] MAMALA, J., BROL, S., JANTOS, J. The estimation of the engine power with use of an accelerometer. SAE Technical Paper 2010-01-0929. 2010. https://doi.org/10.4271/2010-01-0929

[25] KIM, E., CHOI, E. Estimates of critical values of aggressive acceleration from a viewpoint of fuel consumption and emissions. Transportation Research Board 92nd Annual Meeting. Washington 2013.

https://trid.trb.org/view/1242034 
[26] PIELECHA, I., PIELECHA, J. Simulation analysis of electric vehicles energy consumption in driving tests, Eksploatacja i Niezawodnosc - Maintenance and Reliability. 2020, 22(1), 130-137. https://doi.org/10.17531/ein.2020.1.15
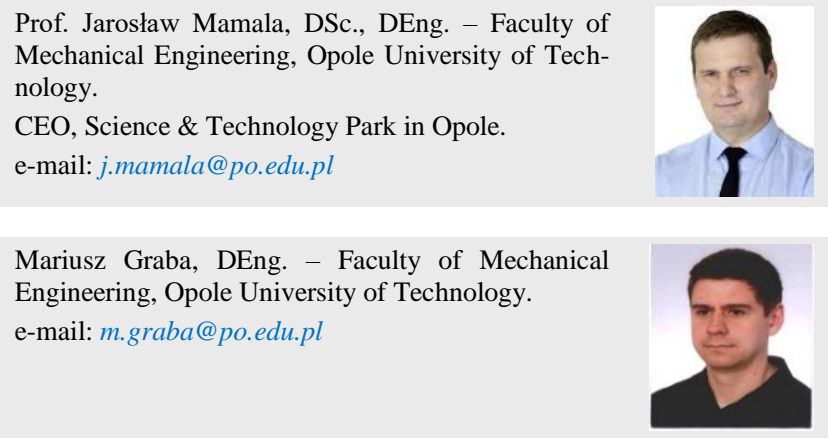

Andrzej Bieniek, DEng. - Faculty of Mechanical Engineering, Opole University of Technology.

e-mail:a.bieniek@po.edu.pl

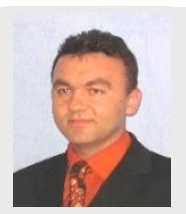

Krzysztof Prażnowski, DEng. - Faculty of Mechanical Engineering, Opole University of Technology.

e-mail:k.praznowski@po.edu.pl
[27] Rover Jaguar Land, Direct injection of gas into a turbine volute, 2016. https://patents.google.com/patent/GB2552482

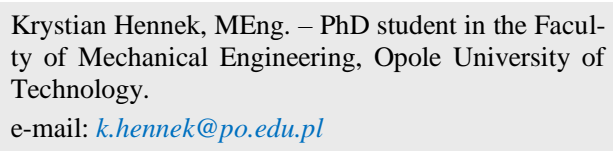

Krystian Hennek, MEng. - PhD student in the Faculty of Mechanical Engineering, Opole University of Technology.

e-mail: k.hennek@po.edu.pl

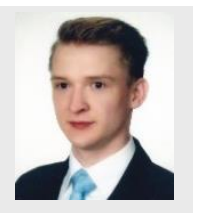

Szymon Kołodziej, DEng. - Faculty of Mechanical Engineering, Opole University of Technology. e-mail: s.kołodziej@po.edu.pl

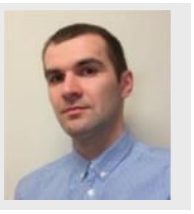

Bartosz Mazurek, MEng. - PhD student in the Faculty of Mechanical Engineering, Opole University of Technology.

R\&D, Science \& Technology Park in Opole.

e-mail: b.mazurek@po.edu.pl

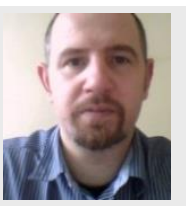

Maciej Sproch, Eng. - student in the Faculty of Mechanical Engineering, Opole University of Technology.

R\&D, Science \& Technology Park in Opole. e-mail:m.sproch@po.edu.pl 